\title{
The effect of training orthopedic nurse specialists in Jiangsu Province of China
}

\author{
Yahui Tong", Hongxia Zhu\#, Jie Wang, Yefang Zou, Hui Gao, Min Cheng \\ Department of Orthopedic, The First Affiliated Hospital of Soochow University, Suzhou, China \\ Contributions: (I) Conception and design: J Wang; (II) Administrative support: None; (III) Provision of study materials or patients: None; (IV) \\ Collection and assembly of data: Y Zou, H Gao, M Cheng; (V) Data analysis and interpretation: Y Tong, H Zhu; (VI) Manuscript writing: All \\ authors; (VII) Final approval of manuscript: All authors. \\ \#These authors contributed equally to this work. \\ Correspondence to: Jie Wang. The First Affiliated Hospital of Soochow University, 188 Shizi Street, Suzhou 215006, China. \\ Email: szsgkhlzwh2020@126.com.
}

\begin{abstract}
Background: The training of orthopedic nurse specialists is gradually increasing in China, but the effect of the training, namely the specialized nursing work carried out by them upon returning to work after training, is unknown. This study aimed to further our understanding of the effect of training orthopedic nurse specialists and provide a basis for improving the training program.

Methods: A total of 201 clinical nurse specialists who graduated from the training base of orthopedic nurse specialists in the Jiangsu Province were interviewed via a self-made questionnaire.

Results: All orthopedic nurse specialists completed a series of specialized nursing work after returning to their posts. In particular, the clinical nurse specialists with senior professional titles participated in more specialized nursing work projects, such as continuous improvement of orthopedic nursing quality, and so on. The influence of having attained different educational levels on the specialized nursing work of orthopedic nurse specialists was not significant.

Conclusions: The orthopedic nurse specialists carried out a series of specialized nursing work after returning to their posts, which not only helps to improve the quality of orthopedic nursing, but also assists in promoting the popularization and homogenization of new knowledge and skills in orthopedic nursing in the Jiangsu Province.
\end{abstract}

Keywords: Orthopedics; clinical nurse specialist; training; specialized nursing work

Submitted Jun 22, 2021. Accepted for publication Sep 18, 2021.

doi: 10.21037/apm-21-2291

View this article at: https://dx.doi.org/10.21037/apm-21-2291

\section{Introduction}

With the transformation of the medical model to the social-psychological-biomedical model, the function of nursing services has gradually expanded from the nursing of disease to "disease prevention, life maintenance, pain relief, and health promotion". The importance of nursing work in maintaining and promoting health is increasing, which heightens the requirements for professional quality of nurses. Accordingly, there will be an increasing demand in the future for nurses with the title of clinical nurse specialist (CNS), a senior clinical nursing worker in various specialized fields (1), and research regarding this role.

After the 1980s, to cope with the growing demands of complex diseases and conditions, improve nursing ability, and patient outcomes (2), the United States of America (USA) gradually began to cultivate a large number of specialist nurses. According to a survey in 2002, there were 67,000 nurse specialists in the USA (3). The USA was the first country to develop nurse specialists and currently has the most experience in this field, having established a very efficient system.

Presently, there is a certain gap between the situation 
of nursing in China and the level of advancement across the world. The education level of nurses is lower than that of clinicians. Nurses are unable to address new problems they encounter at work due to lack of knowledge even if they have innovative awareness. In continuing nursing education training, there is a lack of innovative knowledge training, awareness of innovation is weak, and there are few innovative resources.

The outline of China's Nursing Development Plan [20112015] (4) clearly highlights the necessity of improving the comprehensive quality of the nursing team, to thoroughly implement standardized training of clinical nurse specialists and tutors in the intensive care unit, emergency department, and other fields, strengthen in-service continuing education, and accelerate the training of nurse specialists. Since the Ministry of Health put forward the request, more and more training and certification sessions have been carried out for clinical nurse specialists all over the country. Orthopedic clinical nurse specialist training was one of the earliest such training packages.

\section{Background}

At present, the training of clinical nurse specialists in China mainly involves the following specialties: orthopedics, tumor, diabetes, wound stoma incontinence, emergency, critical care, cardiovascular diseases, operating room, obstetrics, intravenous infusion, pediatric critical care, blood purification, clinical nutrition support, hepatobiliary surgery, psychiatric nursing, neurosurgery, pain, community care and gerontological nursing, and so on (5-8). There are 17 training bases for orthopedic clinical nurse specialists in China, but no research has been conducted on their training effects to date. One of the first training bases was established in Jiangsu. In 2012, the Jiangsu Commission of Health approved the formation of the first training base for orthopedic nurse specialists in the Jiangsu province of China. From its establishment in 2012 to 2019, 201 nurses received training at the training bases. In order to further understand the effect of training orthopedic nurse specialists and provide a basis for further improvement of the training program, this study investigated and analyzed the working status of the 201 orthopedic nurse specialists after they returned to their posts, with specific contents as follows.

\section{Aims}

This study was designed to improve understanding of the training effect of orthopedic nurse specialists and provide a basis for further advancing the training program. We present the following article in accordance with the SURGE reporting checklist (available at https://dx.doi. org/10.21037/apm-21-2291).

\section{Methods}

\section{Study design}

This study was a cross-sectional study.

\section{Participants and procedure}

The survey was conducted in June 2020. From 2012 to 2019, a total of 201 orthopedic nurse specialists were trained. All respondents had participated in the training of orthopedic nurse specialists training base in Jiangsu, and completed 1-month theoretical courses and 2-month practical courses. Finally, they passed theoretical and practical examinations and completed the graduation test organized by Jiangsu Nursing Association. The survey was conducted mainly through WeChat. A questionnaire was created through the Questionnaire Star (https://www.wjx.cn/mobile/statnew.as px?activity=27856824\&reportid=, password: gk67972134) and a $\mathrm{QR}$ code was generated. Then, the $\mathrm{QR}$ code was sent to the WeChat of each class of clinical nurse specialists. The response rate was $100 \%$ (response rate $=$ received questionnaires/sent questionnaires). The questionnaire was established according to the principle: validity, simplicity, humanization, scientificity and innovation. To reduce the subjectivity of the questionnaire, the questions were mainly set as objective questions.

\section{Survey instrument}

The survey instrument was designed based on a literature review and consultation with experts of the field. A total of 5 experts participated in the development of the questionnaire, whose professional specialties were nursing management, orthopedic nursing, and nursing education, respectively. All of the experts had titles of associate director or above and more than 10 years of experience in orthopedic nursing or nursing education. All experts agreed with the items and validity of the questionnaire. There were 29 items in the questionnaire, which was divided into 2 parts. The first part involved the basic data, including gender, age, professional title, education, junior college 
years of work, position, current unit, and so on. The second part was the implementation of specialized nursing practice, including ongoing continuous quality improvement projects, extension nursing projects, standardized training projects of specialized nursing skills, setting up specialized nursing outpatient services, publishing papers, obtaining participants, publishing books, and so on.

\section{Statistical analysis}

Data analysis was performed with the statistical software SPSS 19.0 (IBM Corp., Armonk, NY, USA). The count data were described by percentage and analyzed by chi-square test. Measurement data were expressed as mean \pm standard deviation (SD), and independent sample $t$-test and oneway analysis of variance (ANOVA) were used for statistical analysis. A P value of $<0.05$ was considered statistically significant.

\section{Ethical considerations}

The purpose of the survey was stated at the top of the questionnaire, and all respondents were informed that their information would be kept strictly confidential. All procedures performed in this study involving human participants were in accordance with the Declaration of Helsinki (as revised in 2013). This study was approved by the Ethics Committee of the First Affiliated Hospital of Soochow University in Jiangsu, China (NO.: 177) and informed consent was taken from all the participants.

\section{Results}

\section{Demographic data}

The questionnaire returns-ratio was 100\%. From 2012 to 2019 , a total of 201 orthopedic nurse specialists were trained. These nurses were mainly from second-grade or above hospitals inside and outside of Jiangsu, China. Among these nurses, 12 were not from Jiangsu and 189 were from Jiangsu. All participants were female and the mean age was $36.02 \pm 4.24$ years ( $28-46$ years). At the time of recruitment, $196(97.5 \%)$ nurses had acquired bachelor's degrees and 5 (2.5\%) were master candidates. Distribution of professional titles among participants were as follows: 39 (19.4\%) senior titles, including 1 chief nurse, 38 vice professor nurses; $134(66.7 \%)$ intermediate titles (nurse-in-charge), and 28 $(13.9 \%)$ primary title nurses (nurse practitioner).
Among the cohort, 30 (14.9\%) of nurses had been working as nurses for $<10$ years; $137(68.2 \%)$ for 10 20 years; and $34(16.9 \%)$ for $>20$ years. The distribution of working time in specialty was as follows: 93 (46.2\%) $<10$ years; 100 (49.8\%) 10-20 years; and $8(4.0 \%)>20$ years. Among them, 73 (36.3\%) served as head nurses and 89 $(44.3 \%)$ as nursing team leaders.

\section{Specialized practical work ability}

After having completed the course and returned to their clinical posts, all 201 nurses completed a survey on their specialized practical work ability. All 201 (100\%) orthopedic nurse specialists carried out a series of specialized nursing work, such as designation and implementation of orthopedic nursing guidance, designation and implementation of orthopedic critical patient care plan, home-based nursing guidance of orthopedic patients, and functional exercise guidance of orthopedic patients during the perioperative period (Table 1).

A total of $130(68.0 \%)$ orthopedic nurse specialists carried out the project of continuous nursing quality improvement in clinical practice and acquired encouraging results in the following aspects: orthopedic traction efficiency, correct positioning rate, functional exercise implementation rate, rate of total hip replacement patients getting out of bed, rate of out-of-bed activity, deep vein thrombosis prevention rate, preoperative hyperglycemia screening rate, cervical and lumbar perioperative publicity and education coverage rate and efficiency, pain measures implementation rate, rate of complications related to low-molecular-weight heparin calcium injection, the rate of total hip replacement patients receiving health education knowledge, and so on. There were differences in the status of continuous nursing quality improvement projects carried out by orthopedic nurse specialists with different professional titles $(\mathrm{P}<0.001)$. More projects were implemented by nurse specialists with medium and senior professional titles than those with primary professional titles $(\mathrm{P}<0.01)$, while there was no statistical difference between intermediate and senior professional titles $(\mathrm{P}>0.05)$. However, there was no statistical difference between orthopedic nurse specialists with different education levels $(\mathrm{P}>0.05)$ (Tables 1,2).

A total of 144 (71.6\%) orthopedic nurse specialists carried out standardized orthopedic nursing training in clinical practice. The training involved spinal nerve function 
Table 1 Specialized practical work ability of 201 nurses after returning to their posts

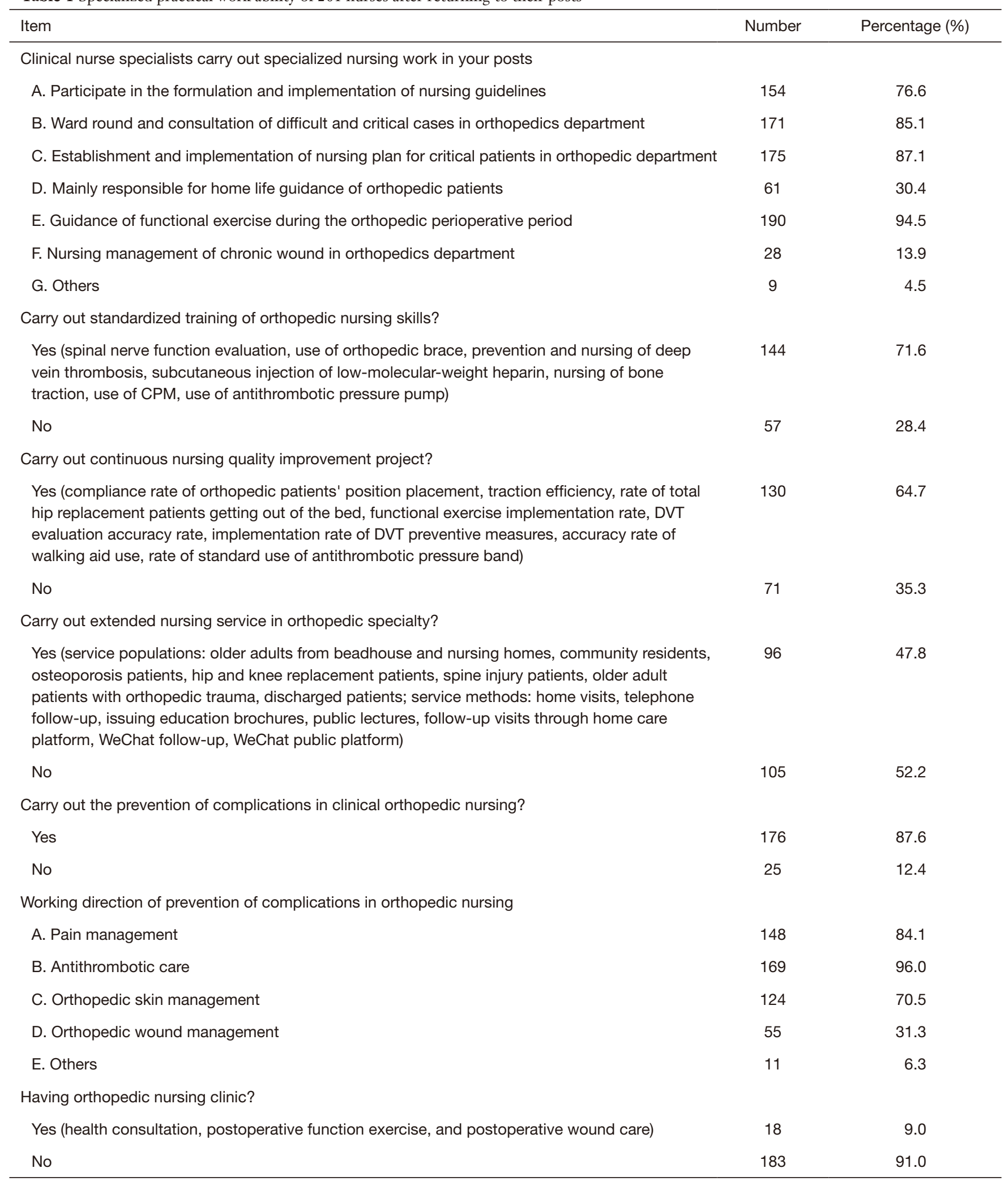

Table 1 (continued) 
Table 1 (continued)

\begin{tabular}{|c|c|c|}
\hline Item & Number & Percentage (\%) \\
\hline Yes & 113 & 56.2 \\
\hline No & 88 & 43.8 \\
\hline \multicolumn{3}{|c|}{ Have obtained patent after becoming a clinical nurse specialist? } \\
\hline No & 153 & 76.1 \\
\hline \multicolumn{3}{|c|}{ Have obtained project approval after becoming a clinical nurse specialist? } \\
\hline Yes & 50 & 24.9 \\
\hline No & 151 & 75.1 \\
\hline \multicolumn{3}{|c|}{ Have published books after becoming a clinical nurse specialist? } \\
\hline No & 194 & 96.5 \\
\hline
\end{tabular}

Table 2 The specialized nursing work carried out by orthopaedic nurse specialists with different professional titles and educational levels

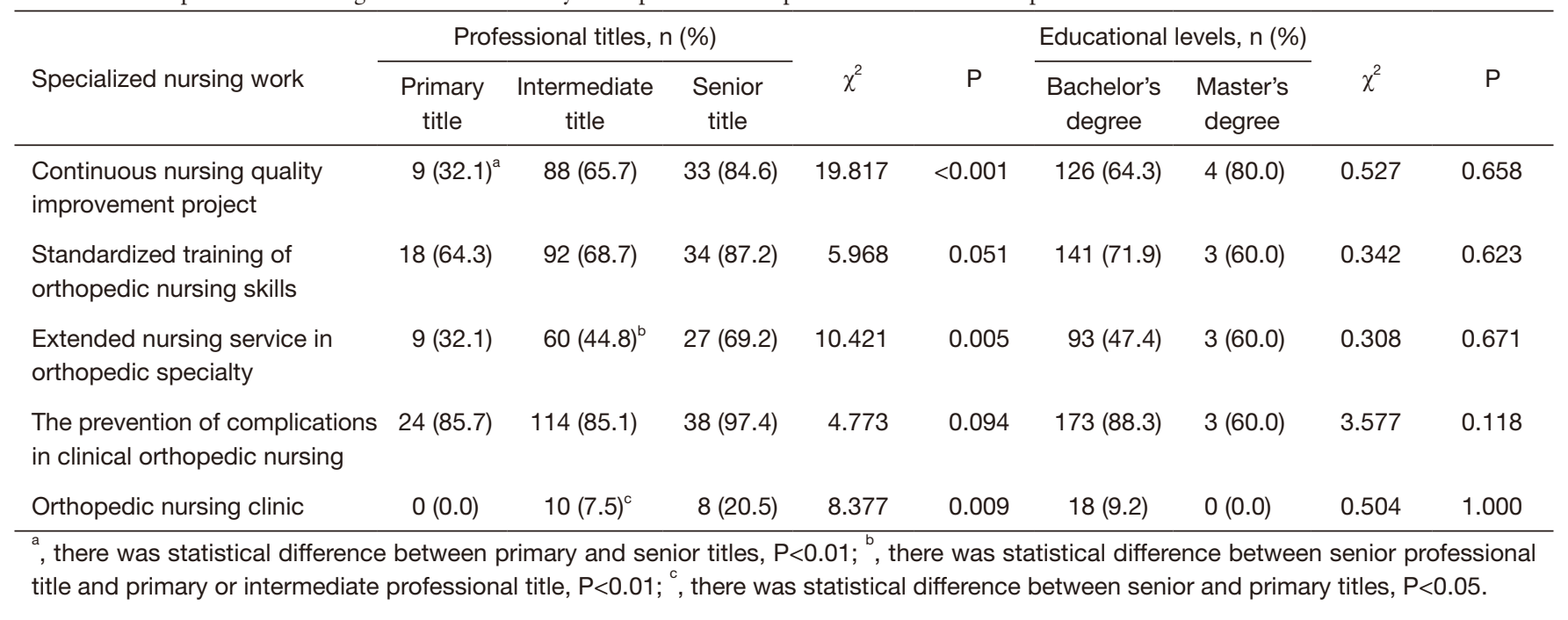

evaluation, vacuum sealing drainage (VSD) replacement, bone traction nursing, continuous passive motion (CPM) operation specification, antithrombotic pressure pump operation specification, antithrombotic pressure band use, low-molecular- weight heparin calcium injection, walker use, and brace wearing. There was no statistical difference between orthopedic nurse specialists with different professional titles and education levels $(\mathrm{P}>0.05)$ (Tables 1,2).

A total of $96(76.0 \%)$ orthopedic nurse specialists carried out extended nursing services in clinical practice. This service was mainly carried out among the populations including patients receiving orthopedic joint replacement, with osteoporosis, receiving cervical and lumbar surgery, with spinal cord injury, and those from nursing homes and the community. Service methods mainly included telephone follow-up, family visit, public lecture, volunteer service, WeChat platform, home-based orthopedic nursing platform, nurse specialist clinic, and so on. There were 
differences in the status of extended nursing service projects carried out by orthopedic nurse specialists with different professional titles $(\mathrm{P}<0.01)$. More projects were carried out by specialist nurse specialists with senior professional titles than those with primary and intermediate titles $(\mathrm{P}<0.01)$, and there was no statistical difference between junior and intermediate titles $(\mathrm{P}>0.05)$. However, there was no statistical difference between orthopedic nurses with different education levels $(\mathrm{P}>0.05)$ (Tables 1,2).

A total of $176(87.6 \%)$ orthopedic nurse specialists carried out the prevention work of orthopedic nursing complications in clinical practice. Their main tasks included pain management, antithrombotic care, orthopedic skin management, and orthopedic wound management. There was no statistical difference between orthopedic nurses with different professional titles and education levels $(\mathrm{P}>0.05)$ (Tables 1,2).

A total of 18 (9\%) orthopedic nurse specialists had conducted orthopedic nursing clinic. Their main work content included health consultation, postoperative functional exercise, postoperative wound care, and so on. There were statistically significant differences in the clinic work status of orthopedic nurse specialists of different professional titles $(\mathrm{P}<0.01)$. More clinics were carried out by nurses with senior professional titles than those with primary professional titles $(\mathrm{P}<0.05)$. There was no statistical difference between primary and intermediate professional titles or between intermediate and senior professional titles $(\mathrm{P}>0.05)$. However, there was no statistical difference between orthopedic nurses with different education levels $(\mathrm{P}>0.05)$ (Tables 1,2).

A total of $113(56.2 \%)$ orthopedic nurse specialists published 281 papers after graduation; 48 (23.9\%) clinical nurse specialists received 82 patents; 50 (24.9\%) orthopedic clinical nurse specialists obtained approval of 67 projects; and $7(3.5 \%)$ published 11 books. There were statistical differences between different titles of orthopedic nurse specialists in papers and patent, and the number of projects $(\mathrm{P}<0.001)$. The number of papers, patents, and projects published by senior titled nurse specialists were more than those with primary and intermediate titles $(\mathrm{P}<0.001)$. There was no statistical difference between primary and intermediate title $(\mathrm{P}>0.05)$.

There were no statistically significant differences in the number of papers and patents published, number of projects obtained, and the number of books published among orthopedic nurse specialists of different educational levels $(\mathrm{P}>0.05)$ (Tables 1,3).

\section{Discussion}

\section{Current status of specialized nursing work of orthopedic nurse specialists in Fiangsu}

The main tasks of orthopedic nursing somewhat different from that of other departments. Orthopedic patient diseases are various. The condition of the is complex and the age of the patients range from child to old people even over 100. The patients can have different degrees of temporary or permanent dysfunction, causing different degrees of harm to the patient's psychological and physiological health. Nurses have to deal with many post-operation complications of patients: (I) anxiety; (II) fear; (III) selfcare defects; (IV) sleep disorders; (V) constipation; (VI) body movement disorder; (VII) pain; (VIII) elevated body temperature; (IX) risk of disuse syndrome; (X) Risk of skin damage; (XI) hemorrhagic shock may occur; (XII) risk of impaired circulation to limbs. The post Thus, the training of the nurses is necessary. After returning to their posts, orthopedic nurse specialists carried out a series of specialized nursing work, including continuous quality improvement of orthopedic nursing, standardized skill training, extended nursing service, prevention of complications of orthopedic nursing, orthopedic nursing clinic, publishing papers and patents, applying for projects, publishing books, and so on. Among them, the most specialized nursing work was the prevention of specialized nursing complications, accounting for $87.6 \%$ of the total population. Thrombotic care and pain management were the most important in the prevention of complications, accounting for $96.0 \%$ and $84.1 \%$, respectively. This may have been related to the increasing recognition of deep vein thrombosis (DVT) by nurses in recent years and gradual realization of the importance of anti-thrombus management (3). The continuous increase of pain management is related to the deepening of the Enhanced Recovery After Surgery (ERAS) concept in recent years, and pain management is an important component of the ERAS concept (9). Standardized training of orthopedic nursing skills and continuous improvement of orthopedic nursing quality were conducted, accounting for $71.6 \%$ and $64.7 \%$, respectively. Improving the quality of specialized nursing has always been the goal of nursing managers, and nursing quality improvement cannot be separated from the above 2 aspects of specialized nursing $(7,10)$. In addition, with the increasing demand for continuous nursing services in orthopedics (1), the number of extended nursing services carried out by orthopedics nurse specialists has gradually increased, 
Table 3 The specialized nursing work carried out by orthopaedic nurse specialists with different professional titles and educational levels

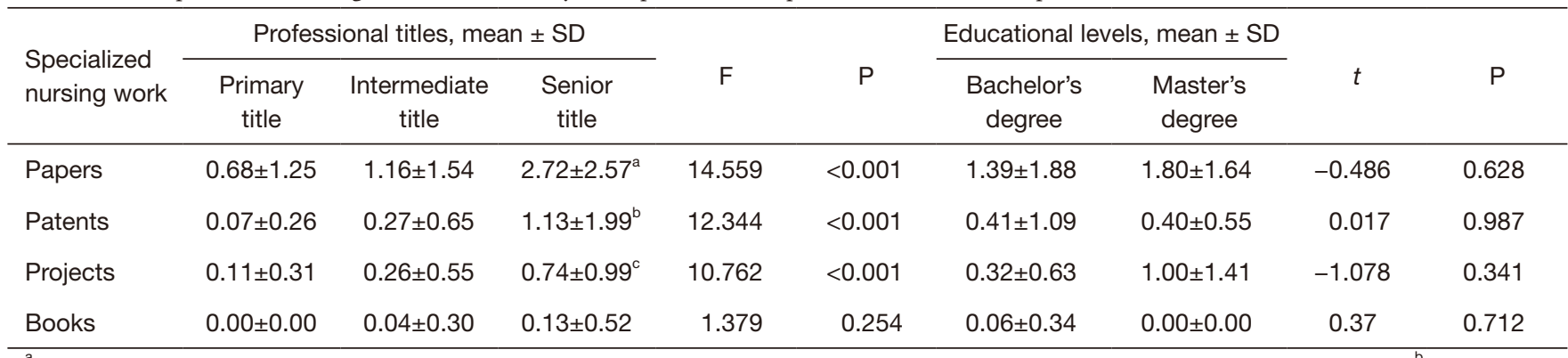

${ }^{a}$, there was statistical difference between senior professional title and primary or intermediate professional title, $\mathrm{P}<0.001 ;{ }^{\mathrm{b}}$, there was statistical difference between senior professional title and primary or intermediate professional title, $\mathrm{P}<0.001 ;{ }^{\mathrm{C}}$, there was statistical difference between senior professional title and primary or intermediate professional title, $\mathrm{P}<0.001$.

accounting for $47.8 \%$. The number of papers published by orthopedic nurse specialists accounted for $56.2 \%$, which was related to the improvement of scientific research ability of specialist nurses after systematic training. Other contents of specialized nursing work were less, including setting up nurse specialist clinics, publishing papers and patents, obtaining participants and publishing books.

\section{The influence of different titles and educational levels on the nursing work of orthopedic nurse specialists}

As shown in Table 2, we found that in the continuous improvement of orthopedic nursing quality, orthopedic extended nursing service, and orthopedic nurse specialists clinic, the situation of specialized nursing work carried out by orthopedic nurse specialists with different professional titles was different, especially that of senior professional titles. This may have been due to the higher requirements of the above specialized nursing work for nurse specialists, requiring orthopedic nurse specialists with stronger specialized nursing ability, richer clinical experience, better ability of solving clinical problems and better communication skills (8). However, for the standardized training of orthopedic nursing skills and prevention of orthopedic nursing complications, the requirements for nurse specialists are not high, and the work may be conducted by nurses with different professional titles. Therefore, there was no significant difference in the performance of clinical nurse specialists with different professional titles.

As shown in Table 3, we detected differences in the number of papers, patents, and topics published by orthopedic nurse specialists with different professional titles, especially that of clinical nurse specialists with senior professional titles. This revealed that orthopedic nurse specialists with senior titles had stronger scientific research ability. This may have been due to the fact that with time, nurses with senior professional titles increasingly gain scientific research related knowledge, have more and more rich clinical experience, and have more scientific research ideas, thus obtaining increased scientific research achievements (11). This level of participation in research is also related to China's national requirements, which stipulate that the promotion of nursing staff title must involve having published papers and patents and obtained research projects. Having these requirements in place encourages clinical nursing specialists to continuously improve their scientific research ability and publish relevant research results (11).

We also found that different educational levels have no significant impact on the specialized nursing work carried out by orthopedic nurse specialists (Tables 2,3), which may be related to the fact that there are less master's degrees among Chinese nurses (12). In this survey, there were only 5 masters, accounting for $2.5 \%$, so educational level had little impact on the whole.

\section{Influence of training base on orthopedic nursing in fiangsu}

The results showed that $94 \%$ of the orthopedic nurse specialists came from the second class and above hospitals in Jiangsu. The training base has trained orthopedic nurse specialists for 118 secondary and tertiary hospitals in Jiangsu. The clinical nurse specialists carried out a series of specialized nursing work after returning to their posts, such as continuous quality improvement of orthopedic nursing, 
extended nursing service, prevention of complications of orthopedic specialty, standardized training of nursing skills, and so on. Due to the different types of orthopedic diseases in secondary and tertiary hospitals, the research basis and platform are different, so the degree of improvement after receiving the same training will be different. However, thanks to this training, the gap between the level of care in secondary and tertiary hospitals has been narrowed. It is not only helpful to improve the quality of orthopedic nursing, but also to promote the popularization and homogenization of new knowledge and skills in orthopedic nursing in the whole province.

\section{Limitations}

The number of orthopedic nurse specialists with master's degree in this study was small, and was shown to have no significant impact on the specialized nursing work. In the future, the enrollment of master degree students could be further expanded to more fully explore the impact of level of education.

\section{Conclusions}

Orthopedic nurse specialists carried out a series of specialized nursing work after returning to their posts, with the prevention of complications of orthopedic surgery being the most popular. Among all professional titles, clinical nurse specialists with senior professional titles carried out the most works. The specialized nursing work of orthopedic nurse specialists trained by Jiangsu orthopedic nurse specialist training base after returning to their posts not only helps to improve the quality of orthopedic nursing, but also helps to promote the popularization and homogenization of new knowledge and skills in orthopedic nursing in Jiangsu Province.

\section{Implications for nursing management}

Orthopedic nurse specialists implement the extent of their roles and advantages in clinical work. Nursing managers should arrange clinical orthopedic nurses to receive professional training to the best of their advantage, which promotes the development of orthopedic nursing.

\section{Acknowledgments}

The researchers would like to thank the participants in the study.

Funding: None.

\section{Footnote}

Reporting Checklist: The authors have completed the SURGE reporting checklist. Available at https://dx.doi. org/10.21037/apm-21-2291

Data Sharing Statement: Available at https://dx.doi. org/10.21037/apm-21-2291

Conflicts of Interest: All authors have completed the ICMJE uniform disclosure form (available at https://dx.doi. org/10.21037/apm-21-2291). The authors have no conflicts of interest to declare.

Ethical Statement: The authors are accountable for all aspects of the work in ensuring that questions related to the accuracy or integrity of any part of the work are appropriately investigated and resolved. All procedures performed in this study involving human participants were in accordance with the Declaration of Helsinki (as revised in 2013). This study was approved by the Ethics Committee of the First Affiliated Hospital of Soochow University in Jiangsu, China (NO.: 177) and informed consent was taken from all the participants.

Open Access Statement: This is an Open Access article distributed in accordance with the Creative Commons Attribution-NonCommercial-NoDerivs 4.0 International License (CC BY-NC-ND 4.0), which permits the noncommercial replication and distribution of the article with the strict proviso that no changes or edits are made and the original work is properly cited (including links to both the formal publication through the relevant DOI and the license). See: https://creativecommons.org/licenses/by-nc-nd/4.0/.

\section{References}

1. Walker J, Gerard PS, Bayley EW, et al. A description of clinical nurse specialist programs in the United States. Clin Nurse Spec 2003;17:50-7.

2. Hodges LC, Knapp R, Edlund B, et al. Patterns of clinical nurse specialist utilization in United States Hospitals. Clin Nurse Spec 1988;2:20-5.

3. He H, Ma X, Su L, et al. Effects of a national quality improvement program on ICUs in China: a controlled pre- 
post cohort study in 586 hospitals. Crit Care 2020;24:73.

4. Li S, Nie S. Effect of orthopedic nursing training on orthopedic nursing quality. Laboratory Medicine and Clinic 2019;16:2508-11.

5. Chen $\mathrm{H}, \mathrm{Pu} \mathrm{L}$, Chen Q, et al. Instrument Development for Evaluation of Gerontological Nurse Specialists Core Competencies in China. Clin Nurse Spec 2019;33:217-27.

6. Liu XL, Wang L. A review of the development and current status of wound ostomy continence nurses in the mainland of China. Int J Nurs Sci 2018;5:105-9.

7. Ren H, Liu C, Wang R, et al. Core Competencies Required for Gastroenterology Nursing Specialists in China. Gastroenterol Nurs 2019;42:169-78.

8. Xing Q, Zhang M, Zhao F, et al. The Development of a Standardized Framework for Primary Nurse Specialists in Diabetes Care in China: A Delphi Study. J Nurs Res 2019;27:e53.

9. Qu L, Liu B, Zhang H, et al. Management of

Cite this article as: Tong Y, Zhu H, Wang J, Zou Y, Gao H, Cheng $M$. The effect of training orthopedic nurse specialists in Jiangsu Province of China. Ann Palliat Med 2021;10(9):94889496. doi: 10.21037/apm-21-2291
Postoperative Pain after Elective Craniotomy: A Prospective Randomized Controlled Trial of a Neurosurgical Enhanced Recovery after Surgery (ERAS) Program. Int J Med Sci 2020;17:1541-9.

10. Liu Z, Zhao Y, Liu D, et al. Effects of Nursing Quality Improvement on Thrombolytic Therapy for Acute Ischemic Stroke. Front Neurol 2018;9:1025.

11. Yu M, Dai F, Yu W, et al. Practice of setting up community chronic disease nursing clinic by specialist nurses from tertiary hospitals. Chinese Nursing Management 2019;19:933-7.

12. Zhang Y, Li G, Liu M, et al. Investigation on transitional care needs and nursing problems at discharge among orthropedic patients. Journal of Nursing Science 2017;32:28-30.

(English Language Editor: J. Jones) 